\title{
NEW WAYS OF TREATMENT IN GERIATRICS AND PERCEPTION OF THOSE METHODS BY PATIENTS
}

\author{
AGNIESZKA KUJAWSKA
}

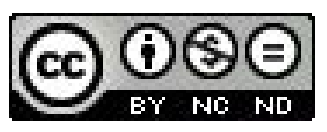

Nicolaus Copernicus University, Collegium Medicum, Departament of Geriatrics, Marii Skłodowskiej Curie 9, 85-094 Bydgoszcz, Poland E-mail address: agajos11@gmail.com

\section{SŁAWOMIR KUJAWSKI}

Nicolaus Copernicus University, Collegium Medicum, Department of Hygiene, Epidemiology and Ergonomics,

Division of Ergonomics and Exercise Physiology, Marii Skłodowskiej Curie 9, 85-094 Bydgoszcz, Poland

E-mail address: slawomirkujawski7@gmail.com

\section{MAŁGORZATA GAJOS}

Nicolaus Copernicus University, Collegium Medicum, Departament of Geriatrics,

Marii Skłodowskiej Curie 9, 85-094 Bydgoszcz, Poland

E-mail address: malgorzata.gajos0904@gmail.com

\section{RADOSŁAW PERKOWSKI}

Nicolaus Copernicus University, Collegium Medicum, Departament of Geriatrics,

Marii Skłodowskiej Curie 9, 85-094 Bydgoszcz, Poland E-mail address: perkowski.radoslaw@gmail.com

\section{JOANNA ANDROSIUK}

Nicolaus Copernicus University, Collegium Medicum, Departament of Geriatrics,

Marii Skłodowskiej Curie 9, 85-094 Bydgoszcz, Poland

E-mail address: joannaandrosiuk@gmail.com

\section{JULITA JARECKA}

Nicolaus Copernicus University, Collegium Medicum, Departament of Geriatrics,

Marii Skłodowskiej Curie 9, 85-094 Bydgoszcz, Poland E-mail address: jjagodzianka@gmail.com 


\title{
MARCIN KOŻUCHOWSKI \\ Nicolaus Copernicus University, Collegium Medicum, Departament of Geriatrics, \\ Marii Skłodowskiej Curie 9, 85-094 Bydgoszcz, Poland \\ E-mail address: marcink12333@gmail.com
}

\section{PAULINA KASPERSKA}

Nicolaus Copernicus University, Collegium Medicum, Departament of Geriatrics,

Marii Skłodowskiej Curie 9, 85-094 Bydgoszcz, Poland E-mail address: paulaakasperskaa@gmail.com

\author{
SYLWIA PŁUSA \\ Nicolaus Copernicus University, Collegium Medicum, \\ Departament of Geriatrics, \\ Marii Skłodowskiej Curie 9, 85-094 Bydgoszcz, Poland \\ E-mail address: sylwia.plusa@gmail.com

\section{WERONIKA TOPKA} \\ Nicolaus Copernicus University, Collegium Medicum, \\ Departament of Geriatrics, \\ Marii Skłodowskiej Curie 9, 85-094 Bydgoszcz, Poland \\ E-mail address: weronika.topka.bydg@gmail.com
}

\begin{abstract}
Developing Western societies are characterized by growing numbers of older people. This trend will increase in coming decades. Medicine and healthcare of developed countries have to stand against new needs of societies rich in people over sixty years old.

This paper will briefly review new technologies and ways of treating disorders of older people on the one hand, and reception of these methods by older patients on the other hand. We briefly describe therapeutic methods used in clinical neuroscience dividing them into 3 categories: therapies based on implantation of external devices into the organism, therapies using video games, and therapies using virtual reality. These therapies will be discussed according to three rules that have been proposed considering the approach to effective therapeutic methods targeting older people.

It can be assumed that older people tend to be afraid of using unknown solutions, even to improve their own health states. Contrary to this claim, most of researches report very high rate of acceptance of the aforementioned techniques by older people. However, laboratory teams should treat older people with extreme care so as to not provoke aversion to technologies used in intervention.
\end{abstract}

Key words: electrical stimulation devices, video games, virtual reality, elderly 


\section{INTRODUCTION}

Dynamic development of neuroscience has resulted in new opportunities in neurotherapy which can be used by clinicians. It raises many ethical questions; as to how much clinicians can interfere into patients' bodies? Moreover, is there a possibility that some day two kinds of people would be established; these who use electrical devices which enhance their brain functions and these who do not. Furthermore, if changing of personality is possible, does it have to be forbidden or not, to name a few. However, it is not the main topic of this document, the reader is directed towards other articles considering man and machine ethical discussions published elsewhere (Keiper, 2006, pp. 4-41; Clausen, 2009, pp. 1080-1081; Mackenzie, 2011, pp. 18-20; Denning, Matsuoka, Kohno, 2009, pp. 1-4).

Increasing numbers of older people in Western countries create challenges which health care authorities of developed countries have never met before. In Poland prediction shows that the group of people who are 65+ years old will account for $23,2 \%$ of whole population in 2035 (Główny Urząd Statystyczny, 2008). The above mentioned demographic situation creates needs for developing new methods of neurotherapy, which will face up to the Geriatric Giants, which include, inter alia: immobility, dementia and depression (Biercewicz, Kędziora-Kornatowska, Marzec, 2006, pp. 133-136).

Methods used in Geriatrics, having regard to the increasing number of older people, should be:

1. Widely available - access to treatment of these disorders should be widespread in all developed countries due to restricted funds of health care providers and patients and limited ability of older people to move.

2. Effective and easy to use - demographic prognosis shows that ageing populations will be characterized by a limited number of people able to work. Thus, most health care providers should be trained in providing these methods, moreover, therapy should offer self-service to patients, even to a small degree, to unburden capacity of health care.

3. It must have as few as possible side effects, and be fun to use - the best therapy or method would not work if it would be not used. Patients have to feel comfortable using it, and not be afraid of using it, even it should provide some fun for them.

In the document we will list and briefly describe techniques that were introduced in the nineties and seem to be good solutions regarding the above mentioned rules, namely: Electrical Stimulation Devices (ESD) - Deep Brain Stimulation (DBS) and Vagus Nerve Stimulation (VNS), therapies based on video games (VGT) and therapies based on virtual reality (VRT). All of the above mentioned methods are based on new technologies, which older people may be not familiar with. Some difficulties may be raised in accepting them by older patients. It is worth examining difficulties that researchers have met while conducting studies based on using these technologies. Moreover, effec- 
tive methods of making older people familiar with unknown technologies should be developed. Inter alia, soft competencies of the laboratory team are crucial for motivating older people into participating in intervention. Such methods would be critical in Health Care as well, where in ideal circumstances, the patient has to be in situation where he or she knows everything he needs to know about therapy to be able to make best free choice in picking up best way of his or her treatment.

\section{ELECTRICAL STIMULATION DEVICES}

\section{Deep Brain Stimulation}

Electrical stimulation was used in Ancient Rome for the first time. It was discovered that treading on a kind of cartilaginous fish, called the torpedo fish could relieve pain related to gout (Gildenberg, 2005, pp. 71-79). Nowadays, electrical stimulation of many body areas are widespread therapy for different symptoms. DBS has now been widely known as a therapy for Parkinson's Disease and tremor (Benabid, Pollak, Hoffmann, et al., 1991, pp. 403-406; Benabid, Pollak, Gao, et al., 1996, pp. 203-214; Bittar, Burn, Bain, et al., 2005, pp. 457-463; Koller, Lyons, et al., 1999, pp. 847-850; Krack, Batir, et al., 2003, pp. 1925-1934) with proven efficiency in treating depression, obsessive-compulsive disorder, Tourette's syndrome and chronic pain symptoms (Bittar, Burn, Bain, et al., 2005, pp. 457-463; Marchand, Kupers, et al., 2003, pp. 481-488; Owen, Green, et al., 2006, pp. 202-206; Lozano, Mayberg, et al., 2008, pp. 461-467; Pereira, Green, et al., 2007, pp. 591-603). Activity of the brain can be managed efficiently by this method. DBS using microelectrodes (f.e. $1.5 \mathrm{~mm}$ length electrode) is characterized by localised effects (affecting in specific ways the structures of the brain near the electrode) which probably could be extended indirectly to other areas by affecting on brain circuits. DBS has changeable parameters (on/ off, amplitude, frequency and pulse width of the current delivered) could be changed easily by the patients themselves in many cases (Allert, Mehnert, et al., 2011, pp. 305-310) . Unfortunately, this method is not without side effects (Williams, Ernst, Birns, 2012, pp. 170; Trachani, Constantoyannis, et al., 2010, pp. 213-217; Halim, Baumgartner, Binder, 2011, pp. 804-806; Hyam et al., 2012, pp. 469-478; Nazzaro, Pahwa, Lyons, 2011, pp. 606-609; Rätsep, Asser, 2012, pp. 547-553; Liu, Shan et al., 2013, pp. 1714-1723). Nonetheless, the last twenty years resulted in more than 100,000 treatments with DBS for movement disorders. An interesting study evaluated patients' own perceptions of living with aforementioned implanted device by using semi structured interviews (Hariz, Hamberg, 2014, pp. 272-278). Totally, 42 patients from Sweden were interviewed ( 31 males and 11 females). Researches proved that a mounted device is rarely an object of worry for patients, even one of patients declared „in a way it has become a part of me". The external part of stimulating device could not be hidden from others, but it was not object of complaints or annoy- 
ance. Even some patients revealed their device to others with premeditation, to share the knowledge about such treatment. Other people showed the device to their relatives only, other patients hid the device, because they worried about other people's thoughts about it. Noteworthy, the main misgiving of patients in studies were not focused on their feelings about their own appearance after the operation or their concerns about impact of stimulator on themselves, their personality or identity or their lives. Their greatest worry was focused on the potential possibility of damaging the device during regular activities (Hariz, Hamberg, 2014, pp. 272-278). In the case of therapies aimed at improving cognitive functioning, several other methods exist, which do not necessarily interfere into patients' bodies. Our brain can be stimulated not only directly, but by taking mental as well as physical activities. Moreover, the risk of changing selfidentity seems to be not an issue in such treatment. However, there are several more issues which will be reviewed in the following paragraphs.

\section{Vagus Nerve Stimulation}

Vagus nerve stimulation is a method based on interval electrical stimulation of the left cervical vagus nerve by an electronic, surgically-implanted generator connected by a lead to the vagus nerve. This method could be useful in relieving symptoms in many diseases; treatment-resistant major depression (TRMD) (Conway, Sheline et al., 2012, pp. 163-171), anxiety (George, Ward et al., 2008, pp. 112-121) or in epilepsy (Ben, Menachem et al., 1994, pp. 616-626), to name a few. Mood disorders (for example depression, anxiety) is one of the so-called Geriatric Giants (George, Ward et al., 2008, pp. 112-121), which significantly lowers quality of life of older people who suffer from these disorders.

Similar to Deep Brain Stimulation, Vagus Nerve Stimulation requires implanting an electrode into a patient's body. The device planted under skin is almost invisible, however, decision-making processes while choosing these kinds of treatment can produce some troubles.

Moreover, despite of the fact that Vagus Nerve Stimulation is not the newest of methods in clinical neuroscience, a letter to the President of Polish National Health Fund of 2012 (National Health Fund, 2012) showed many administrative problems with such intervention, because there were no special codes assigned to this method, which caused problems in funding such operations.

\section{Perception of Electrical Stimulation Devices by patients}

In response to ethical questions postulated in Introduction of this paper, the possibility of creating a class of brain-enhanced people become more realistic than ever. Enhancing of cognitive functioning regarded as normal or above, is now a fact (Farah, Illes et al., 2004, pp. 421-425; McCabe, Knight et al., 2005, pp. 96-106; Sahakian, Morein-Zamir, 2007, pp. 1157-1159). Medicalization of cognitive capacity can lead to a situation, when cognitive performance of people who did not choose to increase it, could be perceived as a pathology (Conrad, 2008). What should be underlined, is the fact that one day, clinical 
neuroscience will give us an opportunity to stand up against the possibility of changing our traits. It seems that willingness to change traits depends on misgivings about influence of this intervention on changing patient's self-identity. Results of questionnaire-based research (Riis, Simmons, Goodwin, 2008, pp. 495-508) showed that participants were most willing to change these traits or cognitive skills who were described as unrelated to their self-identity. On one side it shows the need for ethical discussion and perhaps even legislation concerning boundaries of brain-enhancing interventions, on the other it reveals possible sources of patients' fear related to brain surgery. The need for ethical discussion concerning brain-hardware interfaces is strongly underlined (Clausen, 2011, pp. 495-501).

Adam Keiper (2006) in his essay "The Age of Neuroelectronics” shows some aspects of life of people who decided on Deep Brain Stimulation as a form of treatment for their diseases. He quotes news that Rees Cosgrove, neurosurgeon, shared with the President's Council on Bioethics. He reports a case of a female patient who suffered from Tourette's Syndrome and was treated with Deep Brain Stimulations. Clinicians were able to manipulate functions of the implanted device to boost the patient's creativity. The patient was a graphic designer and her improvement in creativity was noticed by her employer. Another patient reports his preferences about device settings which depend on daily tasks - if he was going to go on social meetings, he preferred settings, which as he claimed, gave him a state of arousal, enhancing articulation and creativity.

The above mentioned cases are really interesting in the light of possibility for a patient to control the functioning of his stimulator by manipulating a handheld therapy controller on his own. However, most patients from a study which considered perception of living with implanted stimulator (Hariz, Hamberg, 2014, pp. 272-278) reported that all patients are informed about the way to manipulate the controller, nevertheless only 7 of them which constituted $17 \%$ of all group claimed that they feel confident while manipulating it on their own needs. Ability for self-management accords with the second rule from Introduction, however in this case it provides some ethical issues that should be discussed.

\section{THERAPIES BASED ON VIDEO GAMES AND THERAPIES BASED ON VIRTUAL REALITY}

\section{Therapies based on video games}

Neurotherapy using new opportunities given by the developing branch of video games entertainment is more frequent nowadays. The Nintendo Wii video games console had been introduced by the media as a powerful method that will give an opportunity to introduce regular physical activities in homes, hospitals and rehabilitation centers in the Western world (Elsworth, 2008; CBS 
news, AP., 2008; Gnyp, 2008). Wii Fit was one of the so called techno hits of 2008 hailed by one of the most popular Polish journals Wprost. Description of the product shows the simple way in which that console differs from others: the gamer has to control the game not by pushing buttons on a controller, but by moving the controller itself. Wii Fit is an another controller which can be plugged in Wii console, in the shape of a platform which the gamer uses by balancing on it (Gnyp, 2008).

Research from 2010 showed that more than half of stroke rehabilitation centers placed in main cities of Australia are equipped with Nintendo Wii console (National Stroke Foundation, 2010). Wii Fit has been marketed as a health and fitness tool and was the first interactive video game to be endorsed by the United Kingdom's National Health Service Change 4 Life program (Gajewski, 2009). Nowadays, PlayStation and Xbox have their own "fit" products . It gives opportunities in neruorehabilitation that were so far unheard of.

However, researches from 2011 (Laver, Ratcliffe et al., 2011, pp. 64) obtained quite pessimistic results. Inclusion criteria for patients who were, inter alia, 65 years old and over, get 21 at least points in Mini Mental State Examination (MMSE) to be medically fit to participate and able to stand up from sitting position without any help. 22 participants had rehabilitation based on Wii Fit supervised by clinician, 25 minutes per day, five days per week. An interesting result from these studies is an observation that at the beginning participants were not highly polarized if they prefer standard or computer-based therapy, however after the implementation of using Wii Fit, they reported an antipathy to using this method and underlined their preferences for using conventional therapy. Their explanation of preferences for conventional therapy was based very often on feeling that this method is more effective .

On the other hand, other studies showed Wii Fit well-acceptance in a community of older people (Joo, Yin et al., 2010, pp. 437-441; Williams, Soiza et al., 2010, pp. 238). Researchers (Laver, Ratcliffe et al., 2011, pp. 64) underline the problem of 'veil of experience' which describes the fact that patients prefer therapy methods which they are used to. Moreover, researches report patient's behaviour which is sometimes called 'ceiling and floor effects' in case of tests of global cognition- some patients find it too hard to resolve, some think that level of complexity of questions are too low, which offends their intelligence (Franco-Marina, García-González et al., 2010, pp. 72-81). Authors (Laver, Ratcliffe et al., 2011, pp. 64) find similar problem with Wii Fit- some may regard is as too complex, some as too childish.

\section{Therapies based on virtual reality}

Virtual reality is an emerging technology (Sveistrup, 2004, p. 10) that could be used as a rehabilitation method by Health Care providers as well by patients on their own. Therefore, it is well fitted to first rule from the Introduction. Moreover, it is rather easy to use after short training, and ready to use at home, because such simulation is produced by electronic devices, which are 
rather handy. Another property of this artificial environment is that it is realtime and interactive, and what is important in to this paper, it is responsive to patient's actions (McComas, Sveistrup, 2002, pp. 55-61) which can be made and/or received in two or three dimensions (Pimentel, Teixeira, 1993). Treatments based on virtual reality were reported as effective tools in increasing cognitive speed and improving mobility and balance (Bisson, Contant et al., 2007, pp. 16-23) in older patients.

Virtual reality also has been used in training patients with dizziness and balance problem as result of labyrinth damage. Participants' subjective assessment showed decrease in the dizziness intensity and improvement of the physical and emotional sensations (Józefowicz-Korczyńska, Walak et al., 2014, pp. 51-57). Another positive consequence of VRT was noted in patients with phobias (Eukowska, 2011, pp. 103-108) and older adults with sleep disturbances (Chang, Wang et al., 2014, pp. 1312-1313). It seems that using this method has a better effect than standard imaging techniques. It concerns especially post traumatic stress disorders (PTSD) patients, specific phobias, anxiety disorder, social fear.

Authors (Jørstad, E. C., Hauer et al., 2005, pp. 501-510) underline that not only physical, but also psychological components are crucial in further posttraumatic rehabilitation. As a consequence there is growing interest in therapy based on virtual reality, including Virtual Reality Exposure Therapy (VRET). One study by Barbara Olasov Rothbaum et al. (1999, pp. 263-271) shows that the application of this of 5 to 7 week therapy significantly decreased PTSD symptoms in Vietnam veterans. Patients participated in 90 minute sessions twice a week, where two different virtual situations were presented. One of them was the helicopter flying over Vietnam and the second was a forest glade surrounded by the jungle. Unfortunately, the researchers were not able to verify their outcomes in randomized study (Ready, Gerardi et al., 2010, pp. 49-54). Joann Difede and Hunter G. Hoffman (2002, pp. 529-535) show that VRET significantly reduced depression and PTSD symptoms measured by the Beck Depression Inventory and the Clinician Administered PTSD Scale in participants after the World Trade Center attack. Other studies including combat in the Gulf War or Iraq veterans also states that the VRET could be effective in relieving symptoms of PTSD patients (Litz, Engel et al., 2007, pp. 1676-1684; McLay, Wood et al., 2011, pp. 223-229; Reger, Holloway et al., 2011, pp. 93-96). Regarding elderly subjects, there is the opportunity to use VRET in treatment, especially when the technology becomes more approachable.

Scientists used VRT in patients with brain injury with hemianopsia, forcing them to pay attention to the neglected part of eyeshot (Eukowska, 2011, pp. 103-108). VRT was applied to patients with traumatic brain injury (Lee, Ku et al., 2003, pp. 383-388). Participant tasks were to move in virtual space of the supermarket picking specified goods for the shopping basket. Patients had to navigate in the virtual supermarket with the joystick, Head Mount Display and 3 Degrees of Freedom Position Sensor. The subjects performed the task 
five times during a period of five days. The system assessed navigation rate, which included elapsed time, distance moved, number of collisions with walls and executive function which included number of selected goods, the number of refrigerator doors opened, number of joystick button presses, error rate. However, the participant group was too small to obtain statistically significant results (Lee, Ku et al., 2003, pp. 383-388). Previous studies showed improvement in various group of patients for example with Alzheimer's Disease and moderate level of Parkinson Disease (Żak Krupnik et al., 2014, pp. 9-13).

VRT has been used in the Tele-Rehabilitation Institute at Rutgers University. Games using the system Rutgers Arm II) called Pick-and-Place, The Treasure Hunt, The Card Island, The Breakout 3D were used. Treatment consisted of 3 sessions every week, lasting up to 1 hour for overall 6 weeks. Participants were post-stroke, their age ranged from 46 to 70 years old. After therapy participants improve their skills in: normal life (ADL), active range of motion, grasp strength, flexion of shoulders, elbows and fingers (Burdea, Cioi, et al., 2011).

\section{Ecological value of Virtual Reality rehabilitation}

Stroke is the third most common cause of death in the world, after heart attacks and cancer diseases,. In the developed countries, $70 \%$ of stroke patients have trouble walking, including 30\% experiencing severe mobility impairments (Banecka-Majkutewicz, Dobkowska et al., 2005, pp. 207-216). Limitation of independent gait function not only reduces functional abilities, but also reduces the quality of life of these patients. One of the main objectives of physiotherapy is to recreate the pattern along with improving of gait, also using virtual reality. Rehabilitation in virtual reality affects the improvement of gait function, improves the function of balance, improving posture control and increased certainty during gait (Banaś, Majchrzycki et al., p. 112). In the virtual environment one can create an individually customized exercise program for the patient. With VR, cortical motor reorganization could be obtained in order to regain functional capacity. Additionally, systematically increasing improvement of executive functions can be gained because the task of using VR can be carried out in relation to the tasks of every day life (Nidhi, Savitata, Abha, 2010, pp. 79-82).

Virtual reality scenarios have also been designed for testing instrumental activities of daily living, including wheelchair navigation (Rizzo, Buckwalter, van der Zaag et al., 2000, pp. 63-70).

There were several projects and research studies developed in the last two decades where computer-based interventions were suggested for memory training and cognitive rehabilitation of elderly people with MCI (mild cognitive impairment) and early-stage dementia.

Virtual reality cognitive training mimics real-world activities (for example using virtual kitchen and cooking) and therefore offers greater potential for transfer to ADLs (Yamaguchi et al., 2012). Training in the virtual supermarket improved also their executive functions (defined as higher-order cognitive functions needed for performing complex tasks) (Kizony, Korman et al.). 


\section{Perception of therapies based on video games and therapies based on virtual reality by patients}

A systematic review (Kueider, Parisi et al., 2012) from 2012 shows effects of different kinds of neurotherapy on improving cognitive functioning in older people. It consists of interventions which included Neuropsychological Software, Classic Cognitive Training Tasks and Video Games. Results suggest that computerized training is an effective and low-cost method to improve cognitive functions of older people (Kueider, Parisi et al., 2012). It is with regard to the first rule mentioned in Introduction of this document, that methods of neurorehabilitation should be widely available due to restricted funds of patients and health care. Moreover, such small-sized electronic devices give an opportunity for home use.

It seems, that a very important aspect in such studies is to have good motivation in participation groups of patients (Torres, 2011, pp. 55-58). This contention, repeats itself in other studies, because it was great adventure and fun for patients, so they determined this method as better and less boring than conventional methods (Józefowicz-Korczyńska, Walak et al., 2014, pp. 51-57). In another study using computer games two participants proclaimed that they did not want to participate in studies, despite the encouragement from research team (Torres, 2011, pp. 55-58). Some of the participants who used Wii Fit exergames, withdrew after the first sessions, because they probably had feelings that unsupervised exergames could be unsafe and they felt uncomfortable in participating in the therapy. The rest of patients rated this method as giving high enjoyment, feeling general improvement, one of them said that his balance was improved and he could do more complicated daily activities (Agmon, Perry et al., 2011, pp. 161-167; Pietrzak, Cotea, Pullman, 2014, pp. 166177). However, some of the patients involved in studies were initially anxious, but they got used to playing games very fast, moreover, gaming provide them positive emotions (Torres, 2011, pp. 55-58).

Some interesting conclusions could be drawn from studies applying VRT to patients with Traumatic Brain Injury (Lee, Ku et al., 2003, pp. 383-388). For example, some patients find it hard to learn a new ability such as using controllers, however, patients which got used to using VR before hospitalization, gained best improvement. Nevertheless, other studies which included aftersroke patients showed that participants have shown acceptance after studying new technologies, they were grateful that they could take part in this study (Burdea, Cioi et al., 2011). Moreover, their mood, morale, attitude to life, selfconfidence (in winning the games or doing tasks with their affected arm) improves because of using new technologies (Burdea, Cioi et al., 2011). Overall, research shows that older people can get fun from using video games (Joo, Yin et al., 2010, pp. 437-441; Williams, Soiza et al., 2010, pp. 238; Torres, 2011, pp. 55-58; Lee, Chen, Hewitt, 2011, pp. 1231-1237; Schmiedek, Bauer, 2010, pp. 59-67) . This is in accordance with the third principle from 'Introduction' section. 
Additional benefit of Nintendo Wii Fit exergames improved social communication with family and the desire to spend time playing exergames together with their grandchildren. The most important reasons, for using virtual reality and video games in the rehabilitation process, announced by patients was higher self-confidence during gait, good motivation associated with the easy scoring system visible during the game (Agmon, Perry et al., 2011, pp. 161-167).

What is worth noting, was the considerable number of participants for studies included in the review (Torres, 2011, pp. 55-58) who had no initial experience in using new technologies such as video games before participating in the study, despite this fact, the neurorehabilitation programme could still be effective. Unfortunately, in some studies (García-Betances, Jiménez-Mixco et al., 2015, pp. 49-54) patients and healthy subjects reported difficulties in interacting with a computer. Patients had more difficulties with the mouse, than the control group, so it is possible that virtual reality could be also used to predict the risk of contracting diseases like $\mathrm{MCI}$ or dementia. The relatively low cost of this virtual environment makes it an attractive and feasible option for wider utilization and implementation in rehabilitation clinics (García-Betances, Jiménez-Mixco et al., 2015, pp. 49-54) .

In a review (Weiss, Rand et al., 2004, p. 12) which describes different rehabilitation methods based on Virtual Reality, it is noted that older participants report high levels of enjoyment from taking part in such rehabilitation. The level of difficulty and perceived effectiveness reported by older patients are at a very good level (Weiss, Rand et al., 2004, p. 12). Moreover, VR probably could be useful in treatment of various disorders. It has proven positive effects on the balance, improving physical fitness. It seems that this method of rehabilitation is potentially the most effective and acceptable for both: medical doctors and their patients (Agmon, Perry et al., 2011, pp. 161-167; Pietrzak, Cotea, Pullman, 2014, pp. 166-177; Rendon, Lohman et al., 2012, pp. 549-552; Duque, Boersma et al., 2013, pp. 257-263) . Chan Tuen Ching et al. (2012, pp. 714-721) reported that $83 \%$ of patients would like continue rehabilitation based on virtual reality at home, and $90 \%$ were happy after this type of exercise although they had no experience of Wii Fit before this study. They were interested in feedback and it made them more motivated. It showed that this method is well accepted by the elderly.

However, in case of neuropsychological therapies based on video games, the most problematic is a first part of second rule, namely the effectiveness. The main issue is lack of scientific proof of effectiveness of computer-based cognitive training. Unfortunately, the results of applying the cognitive training are not optimistic. Although a number of commercial products have arrived on the market in the last decade, Shipstead Zach et al. (2012, p. 628) conclude that contrary to advertisement of these products, there is still, as their review of literature has revealed, lack of scientific proof of cognitive training effectiveness. 


\section{RESULTS}

Both Deep Brain Stimulation and Vagus Nerve Stimulation seems to be effective tools in, to name a few, treating Parkinson's Disease, tremor and treatment-resistant major depression, anxiety, epilepsy, respectively. However this method is not free from side effects, however its overall cost/benefit ratio seems to be fair for patients.

Both, therapies based on video games and therapies based on virtual reality have some proven effectiveness in improving, inter alia, scores in Activities of daily living scale, cognitive speed, mobility and balance, subjective assessment of dizziness, physical and emotional sensations, phobias, sleep disturbances, post traumatic stress disorder symptoms, active range of motion, grasp strength, flexion of shoulders, elbows and fingers. Nevertheless, in case of therapies based on video games and therapies based on virtual reality, described results were obtained on small group sizes. More randomized control trials with larger groups are needed to incorporate these methods into standard clinical therapies for patients.

\section{DISCUSSION}

Therapies for geriatric patients using electrical devices show that fine tuning of the stimulator is important to reach the balance between relief of symptoms and side effects occurrence, therefore the above mentioned method should be improved to increase patient quality of life. Moreover, it shows one more ethical issue of Deep Brain Stimulation- ability to self control it by the patient. First, if Deep Brain Stimulation could enhance their creativity, according to what patients have reported, we can presuppose that coming decades will show what kind of mental functioning could be improved. Likewise, what if the Deep Brain or Vagus Nerve Stimulation could be applied as mind-enhancer of normal functioning people? With a controller on their own, they will be able possibly to gain improvement in their capabilities which could be reversible at any moment. Another issue is protection of such stimulators. Every new technology which reaches popularity at a particular stage of development is exposed to hacker attacks. In case of above mentioned stimulators it could lead to potential harm of patient's health or even death. Last but not least, the already mentioned issue considering possibility of changing personality comes back in this particular topic. What if we are able to manipulate these traits which are strongly correlated with self-identity of patients such as temperament or moral values?

Noteworthy, therapies based on using Electrical Stimulation Devices fulfill some criteria of therapies used in geriatrics from our Introduction. They are not yet widely available nor low-cost, however they seem to be effective. The controller seems to be quite easy to use after brief introduction, however the treatments have some side effects during use, and not all patients find it unproblematic to reveal the fact that they are using such devices. 
Another case is the therapies based on video games and therapies based on virtual reality. Accessibility seems not to be an issue in this case, nor side effects or enjoyment. The majority of patients report that they are able to enjoy using such treatments, especially when they feel support from clinicians and/ or researchers. The most problematic issue seems to be two values of these methods: the effectiveness and ease-of-use. Older participants need an introduction before initiating such therapies, especially if they have little experience of using such items. The effectiveness of cognitive functioning therapy is a field of science which still should be deeper studied to prove it.

\section{REFERENCES}

[1] Agmon, M., Perry, C. K., Phelan, E., Demiris, G., Nguyen, H. Q. (2011). A Pilot Study of Wii Fit Exergames to Improve Balance in Older Adults. Journal of Geriatric Physical Therapy, 34(4), 161-167.

[2] Allert, N., Mehnert, C., Lehrke, R., Maarouf, M., Sturm, V. (2011). Is a Patient Controller for Parkinson's Disease Patients with Subthalamic Nucleus Deep Brain Stimulation Reasonable? Stereotactic and functional neurosurgery, 89(5), 305-310.

[3] Aretouli, E., Brandt, J. (2010). Everyday functioning in mild cognitive impairment and its relationship with executive cognition. International Journal of Geriatric Psychiatry, 25(3), 224-233.

[4] Banaś, A., Majchrzycki, M., Stryła, W., Kruszyński, M., Piotrowska, S. (2013). Technologie wirtualnej rzeczywistości w procesie usprawniania funkcji chodu oraz równowagi u osób po przebytym udarze mózgu [Virtual reality technologies in the process of improving gait and balance functions in patients after stroke]. In: M. Majchrzycki, M. Łańczak-Trzaskowska, E. Gajewska (Eds.). Dysfunkcje narządów ruchu: Diagnostyka i usprawnianie pacjentów z dysfunkcjami narząów ruchu [Dysfunctions of the locomotor system: Diagnosis and rehabilitation of patients with locomotor disabilities]. Poznań: Wydawnictwo Naukowe Uniwersytetu Medycznego w Poznaniu.

[5] Banecka-Majkutewicz, Z. Dobkowska, M., Wichowicz, H. (2005). Analiza czynników ryzyka udaru niedokrwiennego mózgu [Analysis of risk factors for ischemic stroke]. Ann. Acad. Med. Gedan, 35, 207-216.

[6] Benabid, A. L., Pollak, P., Gao, D., Hoffmann, D., Limousin, P., Gay, E., ..., Benazzouz, A. (1996). Chronic electrical stimulation of the ventralis intermedius nucleus of the thalamus as a treatment of movement disorders. Journal of neurosurgery, 84(2), 203-214.

[7] Benabid, A. L., Pollak, P., Hoffmann, D., Gervason, C., Hommel, M., Perret, J. E., ..., Gao, D. M. (1991). Long-term suppression of tremor by chronic stimulation of the ventral intermediate thalamic nucleus. The Lancet, 337(8738), 403-406.

[8] Ben-Menachem, E., Manon-Espaillat, R., Ristanovic, R., Wilder, B. J., Stefan, H., Mirza, W., ..., Wernicke, J. F. (1994). Vagus nerve stimulation for treatment of partial seizures: 1. A controlled study of effect on seizures. Epilepsia, 35(3), 616-626.

[9] Biercewicz, M., Kędziora-Kornatowska, K., Marzec, A. (2006). Wybrane problemy zdrowotne w populacji osób starszych [Selected health problems in the elderly population]. Anales Universitatis Mariae Curie--Skłodowska. Lublin-Polonia, Vil. LX, Suppl, 16(30), 133-136.

[10] Bisson, E., Contant, B., Sveistrup, H., Lajoie, Y. (2007). Functional balance and dual-task reaction times in older adults are improved by virtual reality and biofeedback training. Cyberpsychology \& behavior, 10(1), 16-23.

[11] Bittar, R. G., Burn, S. C., Bain, P. G., Owen, S. L., Joint, C., Shlugman, D., Aziz, T. Z. (2005). Deep brain stimulation for movement disorders and pain. Journal of clinical neuroscience, 12(4), 457-463.

[12] Burdea, G., Cioi, D., Martin, J., Rabin, B., Kale, A., DiSanto, P. (2011). Motor retraining in virtual reality: a feasibility study for upper-extremity rehabilitation in individuals with chronic stroke. Phys Ther, 25. 
[13] CBS news, AP. (2008). Hospitals discover the power of "Wiihab".

[14] Chan, T. Ch., Chan, F., Shea, Y. F., Lin, O. Y., Luk, J. K. H., Chan, H. W. (2012). Interactive virtual reality Wii in geriatric day hospital: A study to assess its feasibility, acceptability and efficacy. Geriatrics Gerontology International, 12, 714-721.

[15] Chang, L.-Ch., Wang, Ch.-Y., Yu, P. (2014). Virtual reality improves sleep quality amongst older adults with disabilities. Geriatric Psychiatry, 29,12, 1312-1313.

[16] Clausen, J. (2009). Man, machine and in between. Nature, 457(7233), 1080-1081.

[17] Clausen, J. (2011). Conceptual and ethical issues with brain-hardware interfaces. Current Opinion in Psychiatry, 24(6), 495-501.

[18] Conrad, P. (2008). The medicalization of society: On the transformation of human conditions into treatable disorders. Baltimore: JHU Press.

[19] Conway, C. R., Sheline, Y. I., Chibnall, J. T., Bucholz, R. D., Price, J. L., Gangwani, S., Mintun, M. A. (2012). Brain blood-flow change with acute vagus nerve stimulation in treatmentrefractory major depressive disorder. Brain stimulation, 5(2), 163-171.

[20] Denning, T., Matsuoka, Y., Kohno, T. (2009). Neurosecurity: security and privacy for neural devices. Neurosurg Focus, 27, 1-4.

[21] Difede, J., Hoffman, H. G. (2002). Virtual reality exposure therapy for World Trade Center post-traumatic stress disorder: A case report. Cyberpsychology $\mathcal{E}$ Behavior, 5(6), 529-535.

[22] Duque, G., Boersma, D., Loza-Diaz, G., Hassan, S., Suarez, H., Geisinger, D., Suriayaarachchi, P., Sharma, A., Demontiero, O. (2013). Effects of balance training using a virtual-reality system in older fallers. Clinical Interventions in Aging, 8, 257-263.

[23] Elsworth C. (2008). Doctors use Nintendo Wii in therapy treatment. The Telegraph. London: Telegraph Media Group.

[24] Farah, M. J., Illes, J., Cook-Deegan, R., Gardner, H., Kandel, E., King, P., ..., Wolpe, P. R. (2004). Neurocognitive enhancement: what can we do and what should we do? Nature reviews neuroscience, 5(5), 421-425.

[25] Franco-Marina, F., García-González, J. J., Wagner-Echeagaray, F., Gallo, J., Ugalde, O., Sánchez-García, S., ..., García-Peña, C. (2010). The Mini-mental State Examination revisited: ceiling and floor effects after score adjustment for educational level in an aging Mexican population. International Psychogeriatrics, 22(01), 72-81.

[26] Gajewski M. (2009). Gra Wii Fit Plus odznaczona przez brytyjski rzad za propagowanie zdrowego stylu życia [Game Wii Fit Plus awarded by the British government for promoting a healthy lifestyle]. Retrieved from: http://www.chip.pl/news/rozrywka/gry-sportowe/2009/10/ gra-wii-fit-plus-odznaczona-przez-brytyjski-rzad-za-propagowanie-zdrowego-stylu-zycia

[27] García-Betances, R. I., Jiménez-Mixco, V., Arredondo, M. T., Cabrera-Umpiérrez, M. F. (2015). Using virtual reality for cognitive training of the elderly. American journal of Alzheimer's disease and other dementias, 30(1), 49-54.

[28] George, M. S., Ward, H. E., Ninan, P. T., Pollack, M., Nahas, Z., Anderson, B., Ballenger, J. C. (2008). A pilot study of vagus nerve stimulation (VNS) for treatment-resistant anxiety disorders. Brain stimulation, 1(2), 112-121.

[29] Gildenberg, P. L. (2005). Evolution of neuromodulation. Stereotactic and functional neurosurgery, 83(2-3), 71-79.

[30] Główny Urząd Statystyczny (2008). Prognoza ludności na lata 2008-2035. Retrieved from: http://www.stat.gov.pl/gus/5840_8708_PLK_HTML.htm

[31] Gnyp, P. (2008). Wii Fit jednym z Technohitów 2008. [Wii Fit one of the Techno hits in 2008] Wprost. Retrieved from: http://polygamia.pl/Polygamia/1,95338,6046710,Wii_Fit_ jednym_z_Technohitow_2008_Wprost.html

[32] Halim, A., Baumgartner, L., Binder, D. K. (2011). Effect of deep brain stimulation on autonomic dysfunction in patients with Parkinson's disease. Journal of Clinical Neuroscience, 18(6), 804-806.

[33] Hariz, G. M., Hamberg, K. (2014). Perceptions of Living With a Device Based Treatment: An Account of Patients Treated With Deep Brain Stimulation for Parkinson's Disease. Neuromodulation: Technology at the Neural Interface, 17(3), 272-278.

[34] Hyam, J. A., Brittain, J. S., Paterson, D. J., Davies, R. J., Aziz, T. Z., Green, A. L. (2012). Controlling the lungs via the brain: a novel neurosurgical method to improve lung function in humans. Neurosurgery, 70(2), 469-478. 
[35] Joo, L. Y., Yin, T. S., Xu, D., Thia, E., Chia, P. F., Kuah, C. W. K., He, K. K. (2010). A feasibility study using interactive commercial off-the-shelf computer gaming in upper limb rehabilitation in patients after stroke. Journal of rehabilitation medicine, 42(5), 437-441.

[36] Jørstad, E. C., Hauer, K., Becker, C., Lamb, S. E. (2005). Measuring the psychological outcomes of falling: a systematic review. Journal of the American Geriatrics Society, 53(3), 501-510.

[37] Józefowicz-Korczyńska, M., Walak, J., Szczepanik, M., Grzelczyk, W. L., Rosiak, O. (2014). Evaluation of Virtual Reality training in the treatment of peripheral vestibular system impairment. Otorynolaryngologia, 13(1), 51-57.

[38] Keiper, A. (2006). The age of neuroelectronics. The New Atlantis, 11, 4-41.

[39] Koller, W. C., Lyons, K. E., Wilkinson, S. B., Pahwa, R. (1999). Efficacy of unilateral deep brain stimulation of the VIM nucleus of the thalamus for essential head tremor. Movement disorders, 14(5), 847-850.

[40] Krack, P., Batir, A., Van Blercom, N., Chabardes, S., Fraix, V., Ardouin, C., ..., Benabid, A. L. (2003). Five-year follow-up of bilateral stimulation of the subthalamic nucleus in advanced Parkinson's disease. New England Journal of Medicine, 349(20), 1925-1934.

[41] Kueider, A. M., Parisi, J. M., Gross, A. L., Rebok, G. W. (2012). Computerized cognitive training with older adults: a systematic review. PloS one, 7(7), e40588.

[42] Laver, K., Ratcliffe, J., George, S., Burgess, L., Crotty, M. (2011). Is the Nintendo Wii Fit really acceptable to older people?: a discrete choice experiment. BMC geriatrics, 11(1), 64.

[43] Lee, B., Chen, Y., Hewitt, L. (2011). Age differences in constraints encountered by seniors in their use of computers and the internet. Computers in Human Behavior, 27(3), 1231-1237.

[44] Lee, J. H., Ku, J., Cho, W., Hahn, W. Y., Kim, I. Y., Lee, S. M., ..., Wiederhold, M. D. (2003). A virtual reality system for the assessment and rehabilitation of the activities of daily living. CyberPsychology \& Behavior, 6(4), 383-388.

[45] Litz, B. T., Engel, C. C., Bryant, R. A., Papa, A. (2007). A randomized, controlled proof-ofconcept trial of an Internet-based, therapist-assisted self-management treatment for posttraumatic stress disorder. The American journal of psychiatry, 164(11), 1676-1684.

[46] Liu, K. D., Shan, D. E., Kuo, T. B., Yang, C. C. (2013). The effects of bilateral stimulation of the subthalamic nucleus on heart rate variability in patients with Parkinson's disease. Journal of neurology, 260(7), 1714-1723.

[47] Lozano, A. M., Mayberg, H. S., Giacobbe, P., Hamani, C., Craddock, R. C., Kennedy, S. H. (2008). Subcallosal cingulate gyrus deep brain stimulation for treatment-resistant depression. Biological psychiatry, 64(6), 461-467.

[48] Łukowska, M. (2011). Zastosowanie technologii wirtualnej rzeczywistości w psychologii. Rocznik Kognitywistyczny, (V), 103-108.

[49] Mackenzie, R. (2011). Who should hold the remote for the new me? Cognitive, affective, and behavioral side effects of DBS and authentic choices over future personalities. AJOB Neuroscience, 2(1), 18-20.

[50] Marchand, S., Kupers, R. C., Bushnell, M. C., Duncan, G. H. (2003). Analgesic and placebo effects of thalamic stimulation. Pain, 105(3), 481-488.

[51] McCabe, S. E., Knight, J. R., Teter, C. J., Wechsler, H. (2005). Nonmedical use of prescription stimulants among US college students: Prevalence and correlates from a national survey. Addiction, 100(1), 96-106.

[52] McComas, J., Sveistrup, H. (2002). Virtual Reality Applications for Prevention, Disability Awareness, and Physical Therapy Rehabilitation in Neurology: Our Recent Work. Journal of Neurologic Physical Therapy, 26(2), 55-61.

[53] McLay, R. N., Wood, D. P., Webb-Murphy, J. A., Spira, J. L., Wiederhold, M. D., Pyne, J. M., Wiederhold, B. K. (2011). A randomized, controlled trial of virtual reality-graded exposure therapy for post-traumatic stress disorder in active duty service members with combat-related post-traumatic stress disorder. Cyberpsychology, behavior, and social networking, 14(4), 223-229.

[54] Morrison, A. B., Chein, J. M. (2011). Does working memory training work? The promise and challenges of enhancing cognition by training working memory. Psychonomic bulletin $\mathcal{E}$ review, 18(1), 46-60.

[55] National Health Fund (2012). Letter to President of Polish. Retrieved from: http:/ / www.bpp.gov. 
pl/gfx/bpp/userfiles/_public/bip/wystapienia_rzecznika/zip-4211-56-12-mc-12-6.11.12. pdf

[56] National Stroke Foundation (2010). National Stroke Audit Rehabilitation Services. Melbourne.

[57] Nazzaro, J. M., Pahwa, R., Lyons, K. E. (2011). The impact of bilateral subthalamic stimulation on non-motor symptoms of Parkinson's disease. Parkinsonism \& related disorders, 17(8), 606-609.

[58] Nidhi K., Savitata M., Abha S. (2010). Virtual reality training: An invaluable tool. Physiotherapy and Occupational Therapy Journal, 3(2), 79-82.

[59] Owen, A. M., Hampshire, A., Grahn, J. A., Stenton, R., Dajani, S., Burns, A. S., ..., Ballard, C. G. (2010). Putting brain training to the test. Nature, 465(7299), 775-778.

[60] Owen, S. L., Green, A. L., Stein, J. F., Aziz, T. Z. (2006). Deep brain stimulation for the alleviation of post-stroke neuropathic pain. Pain, 120(1), 202-206.

[61] Pereira, E. A., Green, A. L., Nandi, D., Aziz, T. Z. (2007). Deep brain stimulation: indications and evidence. Expert review of medical devices, 4(5), 591-603.

[62] Pietrzak, E., Cotea, C., Pullman, S. (2014). Using Commercial Video Games for Falls Prevention in Older Adults: The Way for the Future? Journal of Geriatric Physical Therapy, 37(4), 166-177.

[63] Pimentel, K., Teixeira, K. (1993). Virtual reality through the new looking glass. New York: Intel/ Windcrest.

[64] Products and Procedures (2016). Retrieved from: http://professional.medtronic.com/pt/ neuro/dbs-md/prod/index.htm\#.UXf-aYLgDbY

[65] Rätsep, T., Asser, T. (2012). Subthalamic stimulation improves the cerebral hemodynamic response to the cold pressure test in patients with Parkinson's disease. Journal of Clinical Ultrasound, 40(9), 547-553.

[66] Ready, D. J., Gerardi, R. J., Backscheider, A. G., Mascaro, N., Rothbaum, B. O. (2010). Comparing virtual reality exposure therapy to present-centered therapy with 11 US Vietnam veterans with PTSD. Cyberpsychology, Behavior, and Social Networking, 13(1), 49-54.

[67] Reger, G. M., Holloway, K. M., Candy, C., Rothbaum, B. O., Difede, J., Rizzo, A. A., Gahm, G. A. (2011). Effectiveness of virtual reality exposure therapy for active duty soldiers in a military mental health clinic. Journal of traumatic stress, 24(1), 93-96.

[68] Rendon, A. A., Lohman, E. B., Thorpe, D., Johnson, E. G., Medina, E., Bradley, B. (2012). The effect of virtual reality gaming on dynamic balance in older adults. Age and Ageing, 41, 549-552.

[69] Richmond, L. L., Morrison, A. B., Chein, J. M., Olson, I. R. (2011). Working memory training and transfer in older adults. Psychology and aging, 26(4), 813.

[70] Riis, J., Simmons, J. P., Goodwin, G. P. (2008). Preferences for enhancement pharmaceuticals: The reluctance to enhance fundamental traits. Journal of Consumer Research, 35(3), 495-508.

[71] Rizzo, A., Buckwalter, J. G., van der Zaag, C. (2000). Virtual environment applications in clinical neuropsychology. Proc IEEE Virtual Reality Conf New Brunswick: NJ, 18-22, 63-70.

[72] Rothbaum, B. O., Hodges, L., Alarcon, R., Ready, D., Shahar, F., Graap, K., ..., Baltzell, D. (1999). Virtual reality exposure therapy for PTSD Vietnam veterans: A case study. Journal of traumatic stress, 12(2), 263-271.

[73] Sahakian, B., Morein-Zamir, S. (2007). Professor's little helper. Nature, 450(7173), 1157-1159.

[74] Schmiedek, F., Bauer, C., Lövdén, M., Brose, A., Lindenberger, U. (2010). Cognitive enrichment in old age: Web-based training programs. The Journal of Gerontopsychology and Geriatric Psychiatry, 23(2), 59-67.

[75] Shipstead, Z., Redick, T. S., Engie, R. W. (2010). Does working memory training generalize. Psychologica Belgica, 50(3-4), 245-276.

[76] Shipstead, Z., Redick, T. S., Engle, R. W. (2012). Is working memory training effective? Psychological bulletin, 138(4), 628.

[77] Sveistrup, H. (2004). Journal of NeuroEngineering and Rehabilitation. Journal of neuroengineering and rehabilitation, $1,10$.

[78] Torres, A. C. S. (2011). Cognitive effects of video games on old people. International Journal on Disability and Human Development, 10(1), 55-58.

[79] Trachani, E., Constantoyannis, C., Sirrou, V., Kefalopoulou, Z., Markaki, E., Chroni, E. (2010). 
Effects of subthalamic nucleus deep brain stimulation on sweating function in Parkinson's disease. Clinical neurology and neurosurgery, 112(3), 213-217.

[80] Weiss, P. L., Rand, D., Katz, N., Kizony, R. (2004). Video capture virtual reality as a flexible and effective rehabilitation tool. Journal of neuroengineering and rehabilitation, 1(1), 12.

[81] Williams, M. A., Soiza, R. L., Jenkinson, A. M., Stewart, A. (2010). EXercising with Computers in Later Life (EXCELL)-pilot and feasibility study of the acceptability of the Nintendo® WiiFit in community-dwelling fallers. BMC research notes, 3(1), 238.

[82] Williams, S. E., Ernst, T., Birns, J. (2012). Autonomic failure following deep brain stimulation for Parkinson's disease. British journal of hospital medicine (London, England: 2005), 73(3), 170.

[83] Yamaguchi, T., Foloppe, D. A., Richard, P., Richard, E., Allain P. (2012). A Dual-Modal Virtual Reality Kitchen for (Re)Learning of Everyday Cooking Activities in Alzheimer's Disease. Presence, 21(1), 43-57.

[84] Żak M., Krupnik Sz., Puzio G., Staszczak-Gawełda, I., Stopa, A., Czesak, J. (2014). Making use of virtual reality and console gaming in falls prevention among the elderly. Gerontologia Polska, 22(1), 9-13. 